UNIVERSIDADE DE SÃO PAULO

FACULDADE DE ECONOMIA, ADMINISTRAÇÃO E CONTABILIDADE DEPARTAMENTO DE ADMINISTRAÇÃO PROGRAMA DE PÓS-GRADUAÇÃO EM ADMINISTRAÇÃO

\title{
UMA PROPOSTA PARA DESENVOLVER NOVAS PRÁTICAS PARA O PLANEJAMENTO DA NEGOCIAÇÃO INTERNACIONAL NA PEQUENA EMPRESA: O CASO DO SETOR MÉDICO-HOSPITALAR-ODONTOLÓGICO DA CIDADE DE RIBEIRÃO PRETO
}


Prof. D ra Suely Vilela

Reitora da Universidade de São Paulo

Prof. Dr. Carlos Roberto Azzoni

Diretor da Faculdade de Economia, Administração e Contabilidade

Prof. Dr. Isak Kruglianskas

Chefe do Departamento de Administração

Prof. Dr. Lindolfo Galvão de Albuquerque

Coordenador do Programa de Pós-Graduação em Administração 


\section{UMA PROPOSTA PARA DESENVOLVER NOVAS PRÁTICAS PARA O PLANEJAMENTO DA NEGOCIAÇÃO INTERNACIONAL NA PEQUENA EMPRESA: O CASO DO SETOR MÉDICO-HOSPITALAR-ODONTOLÓGICO DA CIDADE DE RIBEIRÃO PRETO}

Tese apresentada ao Departamento de Administração, da Faculdade de Economia, Administração e Contabilidade da Universidade de São Paulo, com requisito para a obtenção do título de Doutora em Administração.

Orientador Prof. Dr. Dante Pinheiro Martinelli.

\section{SÃO PAULO}


Tese defendida e aprovada no Departamento de Administração da Faculdade de Economia, Administração e Contabilidade da Universidade de São Paulo - Programa de Pós-Graduação em Administração, pela seguinte banca examinadora:

\section{FICHA CATALOGRÁFICA}

\section{Elaborada pela Seção de Processamento Técnico do SBD/FEA/USP}

Garcia, Sheila Farias Alves

Uma proposta para desenvolver novas práticas para o planejamento da negociação internacional na pequena empresa : o caso do setor médico-hospitalar-odontológico da cidade de Ribeirão Preto / Sheila Farias Alves Garcia. -- São Paulo, 2006.

$174 \mathrm{p}$.

Tese (Doutorado) - Universidade de São Paulo, 2006

Bibliografia

1. Negociação (Administração) 2. Administração de serviços de saúde - Ribeirão Preto 3. Pequenas e médias empresas I. Universidade de São Paulo . Faculdade de Economia, Administração e Contabilidade. II. Título.

$$
\text { CDD }-658.4052
$$

